\title{
Angiographic and Clinical Outcomes After Sirolimus- Eluting Stent Implantation to De Novo Ostial Lesion of the Right Coronary Artery
}

\section{A Retrospective Study}

\author{
Hiroshi Sakamoto, MD*,**; Tetsuya Ishikawa, MD*; Makoto Mutoh, MD*; \\ Kamon Imai, MD*; Seibu Mochizuki, MD**
}

\begin{abstract}
Background Although ostial lesion (defined as being within $3 \mathrm{~mm}$ of the ostia) of the right coronary artery (RCAos) has been a limitation of percutaneous coronary intervention after using previous various devices, the angiographic and clinical outcomes after the deployment of a sirolimus-eluting stent (SES) to RCAos have not been fully estimated. Therefore, the incidences of binary restenosis (BR; \% diameter stenosis at chronic phase $\leq 50$ ) and target lesion revascularization (TLR) after SES to RCAos were retrospectively compared with those after SES to RCA proximal (RCApro) and those after bare metal stents (BMS) to RCAos.

Methods and Results The ratios of BR (18.9\%) and TLR (13.5\%) after SES to RCAos ( $\mathrm{n}=37$, mean follow-up interval of each group was 249 days) were significantly decreased compared with those of BMS to RCAos (41.7\%, 36.1\%, $\mathrm{p}<0.01$, respectively) ( $\mathrm{n}=36,194$ days), but were significantly increased compared with those of SES to RCApro $(4.84 \%, 1.61 \%, p<0.01$, respectively) $(n=62,240$ days). There were no incidences of death, myocardial infarction, and definite stent thrombosis during the observational intervals in the entire cohort of 125 patients.

Conclusions RCAos has to be taken into consideration as one of the limitations of SES because of the marked increase in the incident ratios of BR and TLR compared with those of RCApro, although SES demonstrated a likewise benefit compared with BMS. (Circ J 2008; 72: 880-885)
\end{abstract}

Key Words: Binary restenosis; Ostial lesion; Right coronary artery; Sirolimus-eluting stent; Target lesion revascularlization

$\mathbf{S}$ irolimus-eluting stent (SES) (Cypher ${ }^{\circledR}$, Cordis/Johnson \& Johnson, New Brunswick, NJ, USA) has been widely deployed to various types of lesions because of its promising data about the markedly reduced incidence of target lesion revascularization (TLR) with in-stent restenosis (ISR) compared with that of conventional bare metal stents (BMS)1,2 However, several predictors for ISR and TLR after SES implantation have been reported?,4 In addition, although the molecular mechanism of ISR after SES implantation has been well studied, the optimal method for ISR inside SES has not been fully explored6 Therefore, complete revascularization against ischemic coronary diseases by percutaneous coronary intervention (PCI) has not been achieved despite the upcoming era of the drug-eluting stent (DES).

Ostial lesion of the right coronary artery (RCAos; which

(Received October 4, 2007; revised manuscript received December 4, 2007; accepted December 26, 2007)

*Division of Cardiology, Saitama Prefecture Cardiovascular and Respiratory Center, Saitama, **Division of Cardiology, Department of Internal Medicine, The Jikei University School of Medicine, Tokyo, Japan

Mailing address: Hiroshi Sakamoto, MD, Division of Cardiology, Department of Internal Medicine, The Jikei University School of Medicine, 3-25-8 Nishi-Shimbashi, Minato-ku, Tokyo 105-8461, Japan. E-mail: cy25e@jikei.ac.jp

All rights are reserved to the Japanese Circulation Society. For permissions, please e-mail: cj@j-circ.or.jp is defined as the lesion being within $3 \mathrm{~mm}$ of the ostia) has been a limitation of PCI because of its high ratio of restenosis after using various devices before the availability of the DES?-13 Furthermore, RCAos is reported to be the most powerful predictor for TLR after SES implantation, 3,4 although SES brings greater benefits for stenting to RCAos compared with BMS 14,15 Therefore, in the present study, the angiographic and clinical outcomes after SES implantation to RCAos were retrospectively estimated. For this purpose, binary in-stent restenosis and TLR after SES implantation to de novo RCAos were compared with those of BMS and also with those of post-SES implantation to the de novo RCA proximal (RCApro; which is defined as the lesion beyond $3 \mathrm{~mm}$ distal from the ostia).

\section{Methods}

\section{Study Population}

The SES was approved in August 2004 in Japan; hence, after obtaining informed consent, the SES was routinely deployed, as described in our previous reports, 16,17 Briefly, the SES was routinely implanted in patients unless there was a known malignancy, pre-surgical operation, severe anemia, and the existence of various social conditions. Thus, those patients with BMS enrolled in the present study had received their implants before SES technology was approved. The quantitative coronary angiogram (QCA) data of RCAos (SES-RCAos group, $\mathrm{n}=37$ ) and RCApro (SES-RCApro 
Table 1 Comparison of the Variables After Implantations of SES and BMS to RCA Ostial Lesions and SES to RCA Proximal Lesions

\begin{tabular}{|c|c|c|c|}
\hline & SES-RCAos & BMS-RCAos & SES-RCApro \\
\hline Number & 37 & 36 & 62 \\
\hline \multicolumn{4}{|l|}{ Patient characteristics } \\
\hline Age (years, $\pm S D)$ & $68 \pm 8.3$ & $66 \pm 11.4$ & $67 \pm 9.9$ \\
\hline Male (\%) & 73.0 & 55.6 & 74.2 \\
\hline Hypertension (\%) & 81.1 & $69.4 *$ & $77.4^{*}$ \\
\hline Diabetes mellitus (\%) & 48.6 & 52.8 & 40.3 \\
\hline Hyperlipidemia (\%) & 59.5 & $36.1 *$ & $37.1 *$ \\
\hline$E F<40 \%(\%)$ & 2.7 & 2.8 & 8.1 \\
\hline \multicolumn{4}{|l|}{ Lesion location } \\
\hline Type B2/C (\%) & 78.4 & 77.8 & $50.0^{*}$ \\
\hline Calcification $(\%)$ & 5.4 & 19.5 & 3.2 \\
\hline Chronic total occlusion (\%) & 13.5 & 16.7 & 6.45 \\
\hline $\operatorname{AMI}(\%)$ & 8.1 & $22.2 *$ & $24.2 *$ \\
\hline Prior myocardial infarction (\%) & 43.2 & 30.6 & $24.2 *$ \\
\hline Multi-VD (\%) & 56.8 & 58.3 & 41.9 \\
\hline Rotablator (\%) & 0 & $13.9 *$ & 1.6 \\
\hline IVUS-guide (\%) & 97.3 & 91.7 & 91.9 \\
\hline \multicolumn{4}{|l|}{ Procedural characteristics } \\
\hline Stent number & $1.95 \pm 0.91$ & $2.14 \pm 1.20$ & $1.27 \pm 0.52 *$ \\
\hline Stent diameter $(\mathrm{mm})$ & $3.58 \pm 0.51$ & $3.74 \pm 0.51$ & $3.42 \pm 0.50$ \\
\hline Stent length $(\mathrm{mm})$ & $27.0 \pm 14.9$ & $16.9 \pm 7.43 * *$ & $29.5 \pm 13.1$ \\
\hline Maximum pressure $(\mathrm{atm})$ & $20.9 \pm 3.32$ & $16.7 \pm 2.75 * *$ & $20.4 \pm 3.45$ \\
\hline
\end{tabular}

${ }^{*} p<0.05$ and $* * p<0.01$ compared with the variables in the SES-RCAos group.

Variables after sirolimus-eluting stent (SES) implantation to an ostial lesion of the right carotid artery (SES-RCAos) were compared with those after bare metal stent (BMS) implantation to RCA ostial lesion (BMS-RCAos) and with those after SES implantation to $R C A$ proximal lesions (SES-RCApro). Continuous variables are expressed as the mean $\pm S D$, and discrete variables are given as percentages.

Male, the ratio of male sex; $E F<40 \%$, left ventricular dysfunction (ejection fraction $<40 \%$ ); Type B2/C, complex lesion classified as type B2/C, in accordance with the American College Cardiology/American Heart Association task classification; AMI, acute myocardial infarction; Multi-VD, multiple vessel disease; Rotablator, use of rotablator; IVUS-guide, the availability of intravascular ultrasonography; Stent number, the number of implanted stents per lesion; Stent diameter, the maximum balloon size used to expand the stent; Stent length, the total stented segment length; Maximum pressure, the ballooning pressure used by the maximal size balloon.

group, $\mathrm{n}=62$ ) (as defined above) after SES implantation were obtained by performing follow-up coronary angiography (f-CAG) during the period from January 2003 to September 2005, and the data after BMS implantation to RCAos was also obtained during the same period (BMSRCAos group, $n=36$ ). All 135 procedures were successful and the percentage diameter stenosis (\%DS) by QCA immediately after procedure (post-procedural \%DS) was $<25 \%$. There were no in-hospital major adverse cardiovascular events (MACE) composite of death, Q-wave myocardial infarction, emergent coronary artery bypass grafts $(\mathrm{CABG})$ or definite early stent thrombosis, as defined by ARC described in the United States Food and Drug Administration (FDA) statement ${ }^{18}$ Myocardial infarction was defined as Q-wave formation in more than 2 leads and having the maximum level of serum creatine kinase (peak CK) $>400 \mathrm{IU} / \mathrm{L}$.

Procedure of Intravascular Ultrasonography (IVUS), Stenting and Rotablator During PCI Procedure

The procedure for PCI is described elsewhere in our previous reports, 46,17 Briefly, the procedure was undergone with a 6-, 7- or 8-Fr guiding catheter via radial, brachial or femoral arteries. Heparin (3,000-5,000 IU) was administered intravenously during the procedure.

The use of IVUS (Atlantis ${ }^{\circledR}$ SR pro; Boston Scientific Scimed, Inc, Maple Grave, MN, USA) was encouraged to obtain an intravascular assessment of the geometry and complete stent apposition 19,20 As shown in Table 1, the availabilities of IVUS (IVUS-guide) were more than $90 \%$ in all 3 groups. However, the percentage of IVUS-guide was the composite of pre-procedural, during the procedure before stenting (after pre-dilatation by ballooning), before post-dilatation by ballooning after stenting, and post-procedural intravascular assessments. As the targeted lesions were either ostial or proximal sites of the RCA, pre-dilatation was usually performed. In addition, there were many cases in which post-procedural IVUS assessment could be performed after stenting to RCAos due to the modification of the stented vessel.

The selection of BMS among the various kinds available was dependent upon the operator's discretion, without any prospective randomization. As mentioned above, BMS were implanted before SES had been approved in Japan. The kinds of BMS used were as follows: Multi-Link PENTATM (Abbott Vascular, Santa Clara, CA, USA) ( $\mathrm{n}=11,30.6 \%)$; Express (Boston Scientific, Natick, MA, USA) (n=7, 19.4\%); NIR (Boston Scientific) ( $\mathrm{n}=5,13.9 \%)$; BX Velocity (Cordis/ Johnson \& Johnson) $(\mathrm{n}=4,11.1 \%)$; Multi-Link ZETA ${ }^{\circledR}$ (Abbott Vascular) $(\mathrm{n}=4,11.1 \%)$; Duraflex ${ }^{\mathrm{TM}}$ (GOODMAN Corp, Nagoya, Japan) $(\mathrm{n}=2,5.6 \%)$; DRIVER (Medtronic, Inc, Minneapolis, MN, USA) $(\mathrm{n}=1,2.8 \%)$; Tsunami (TERUMO Corp, Tokyo, Japan) $(\mathrm{n}=1,2.7 \%)$; and MultiLink TRISTAR ${ }^{\mathrm{TM}}$ (Abbott Vascular) $(\mathrm{n}=1,2.8 \%)$.

Stents were deployed in order to cover the targeted lesion fully and not to implant the edges on the plaque-rich area, as identified by angiographic assessment and/or intravascular assessment with IVUS. In order to expand the proximal site of the stent at the RCAos, the guiding catheter was intentionally rolled with the inflated balloon. When more than 2 stents were needed, these were implanted without any gap by angiogram. When further stent dilatation 
Table 2 Comparison of the QCA Data and MACE in the 3 Groups

\begin{tabular}{|c|c|c|c|}
\hline & SES-RCAos & BMS-RCAos & SES-RCApro \\
\hline Number & 37 & 36 & 62 \\
\hline \multicolumn{4}{|l|}{ Pre-procedure } \\
\hline$M L D(\mathrm{~mm})$ & $0.88 \pm 0.59$ & $0.92 \pm 0.53$ & $1.03 \pm 0.65$ \\
\hline$\% D S(\%)$ & $70.7 \pm 18.9$ & $69.2 \pm 17.5$ & $63.1 \pm 24.1$ \\
\hline$R D(\mathrm{~mm})$ & $2.93 \pm 0.57$ & $3.00 \pm 0.67$ & $2.85 \pm 0.60$ \\
\hline Lesion length (mm) & $13.4 \pm 14.0$ & $11.8 \pm 10.3$ & $14.8 \pm 10.6$ \\
\hline \multicolumn{4}{|l|}{ Post-procedure } \\
\hline$M L D(\mathrm{~mm})$ & $3.35 \pm 0.47$ & $3.39 \pm 0.57$ & $3.08 \pm 0.43^{*}$ \\
\hline$\% D S(\%)$ & $4.81 \pm 8.36$ & $6.75 \pm 10.4$ & $5.58 \pm 9.76$ \\
\hline$R D(m m)$ & $3.54 \pm 0.52$ & $3.66 \pm 0.55$ & $3.27 \pm 0.43^{*}$ \\
\hline Acute gain $(\mathrm{mm})$ & $2.47 \pm 0.68$ & $2.47 \pm 0.82$ & $2.04 \pm 0.69 *$ \\
\hline \multicolumn{4}{|l|}{ Chronic phase } \\
\hline Interval (day) & $243 \pm 93.0$ & $194 \pm 71.2 *$ & $240 \pm 85.4$ \\
\hline$M L D(\mathrm{~mm})$ & $2.51 \pm 0.81$ & $1.94 \pm 0.84 *$ & $2.63 \pm 0.64$ \\
\hline$\% D S(\%)$ & $25.4 \pm 22.2$ & $40.5 \pm 24.5 *$ & $19.8 \pm 14.3$ \\
\hline$R D(m m)$ & $3.37 \pm 0.45$ & $3.24 \pm 0.62$ & $3.29 \pm 0.58$ \\
\hline Late luminal loss $(\mathrm{mm})$ & $0.84 \pm 0.71$ & $1.46 \pm 0.81 * *$ & $0.45 \pm 0.48^{*}$ \\
\hline Binary restenosis (\%) & 18.9 & $41.7^{*}$ & $4.84 *$ \\
\hline Focal ISR (\%) & 71.4 & $6.7 *$ & 33.3 \\
\hline MACE, $n(\%)$ & $5(13.5)$ & $13(36.1) *$ & $1(1.61) *$ \\
\hline$T L R, n(\%)$ & $5(13.5)$ & $13(36.1)^{*}$ & $1(1.61) *$ \\
\hline$C A B G, n(\%)$ & $1(2.7)$ & $2(5.6)$ & 0 \\
\hline
\end{tabular}

$* p<0.05$ and $* * p<0.01$ compared with the variables in SES-RCAos.

The quantitative coronary angiogram (QCA) parameters used in the 3 phases (ie, pre-procedure, post-procedure, and chronic phase) and the incident ratio of major adverse clinical event (MACE) were compared in the 3 groups (see Table 1 for description of groups). Continuous variables among QCA data were expressed as the mean $\pm S D$, and discrete variables in MACE are given as percentages. MACE composite of death, myocardial infarction, and incidence of target lesion revascularization (TLR) composite of repeated percutaneous coronary intervention or coronary artery bypass grafting $(C A B G)$.

$M L D$, minimal lumen diameter; \%DS, percentage diameter stenosis; $R D$, reference diameter; Acute gain, post-procedural minimum lumen diameter minus pre-procedural minimum lumen diameter; Late luminal loss, post-procedural minimum lumen diameter minus minimum lumen diameter at chronic phase; Binary restenosis, \%DS at chronic phase $>50$; Focal ISR, lesion length within $10 \mathrm{~mm}$ at chronic phase. See Table 1 for explanation of other abbreviations.

was needed, high-pressure ballooning with a non-compliant balloon was usually done.

The use of a rotablator was not randomized and depended upon the operator's discretion. At our center, a rotablator was used in cases in which the inflated balloon was indented (ie, stents were not implanted without pulverizing the calcification by rotablator in case the balloon was not fully dilated). This strategy was consistent for several years, regardless of the type of stent used (ie, BMS or SES).

In cases of emergent stenting, use of the distal protection method with a PercuSurge GaurdWire ${ }^{\circledR}$ device (Medtronic AVE CO, Santa Rosa, NM, USA) was encouraged, particularly at stenting the culprit in order to refrain from establishing angiographic slow flow or no reflow phenomenon during the procedure.

\section{Anti-Platelet Therapy}

As described elsewhere, $, 16,17$ at our cardiovascular center, clopidogrel $^{21}$ was used from September 2004 as the third anti-platelet therapy, and we started to routinely implant SES under the back-up of clopidogrel, not only for elective PCI but also for emergent PCI after obtaining the patient's informed consent. Anti-platelet therapy after BMS and SES implantation are described elsewhere $4,16,17$ Briefly, in cases of elective stenting, aspirin (162-200 mg) and ticlopidine $(200 \mathrm{mg})$ were given orally immediately after the patient's clinical diagnosis. In cases of elective stenting, ticlopidine (200 mg/day) was prescribed 10-14 days before a planned PCI. After stenting, ticlopidine was prescribed during at least 2 weeks after BMS and at least 12 weeks after SES implantations, in addition to aspirin (81-100 mg/day). If the patient showed any adverse effects to ticlopidine, treatment was altered to cilostazol (200-300 mg/day). Similarly, if the patient showed any adverse effects to cilostazol, treatment was altered to clopidogrel. The duration of dual anti-platelet therapy and the timing of discontinuation of dual anti-platelet therapy to aspirin alone were not prospectively assigned but were dependent upon the doctor's discretion.

\section{Data of Quantitative Coronary Angiography}

In the BMS-RCAos group, f-CAG was planned after 6 months $^{22}$ post-BMS implantation. In both SES groups, f-CAG was planned 6-12 months ${ }^{17,23}$ post-SES implantation.

The parameters of QCA were obtained at 3 points: before PCI (pre-procedure); immediately after successful PCI (post-procedure); and at the chronic phase (chronic phase), by measuring with a TCS cardiovascular network system (CAAS-2 system; The Netherlands), as described elsewhere ${ }^{17}$ The parameters included the minimal lumen diameter (MLD), \%DS (as defined above), reference diameter (RD), and lesion length. In addition, acute gain (ie, postprocedural minimum lumen diameter minus pre-procedural minimum lumen diameter) and late luminal $\operatorname{loss}^{24}$ (ie, postprocedural minimum lumen diameter minus minimum lumen diameter at chronic phase) were calculated. Binary in-stent restenosis (ie, binary restenosis) was defined as having a $\% \mathrm{DS} \leq 50$ at the chronic phase. In accordance with Mehran and colleagues, ISR was assigned as either focal type (ie, lesion length at chronic phase $\geq 10 \mathrm{~mm}$; type I) or diffuse type (ie, $<10 \mathrm{~mm}$; types II, III or IV) ${ }^{25}$ The ratio of focal type ISR in the SES-RCAos group was then com- 
pared with those in the BMS-RCAos and SES-RCApro groups.

\section{Variables and Definitions}

The main purpose of the present study was to estimate the angiographic and clinical outcomes among the 3 experimental groups. Therefore, as a measure for angiographic outcome, binary restenosis (as defined above) was compared among the 3 groups. As a measure for clinical outcome, the incident ratio of major adverse cardiac event (MACE) composite of death, myocardial infarction, and TLR (composite of repeated PCI or CABG) was retrospectively estimated. In addition, although stent thrombosis was not included in the category for ISR, the incidence of angiographically documented definite late ( $>30$ days post-implantation) stent thrombosis (LST) needing TLR was also included in the end-point. Definite LST was classified according to the definition by the ARC; that is, as either definite, probable or possible, and as early (0-30 days) or late ( $>30$ days), as described in the recent overview by the US FDA ${ }^{18}$ Definite stent thrombosis was defined as the presence of an acute coronary syndrome with angiographic or autopsy evidence of thrombus or occlusion. However, as shown in Table 2, MACE without TLR did not occur. Thus, the incident ratio of TLR is mainly discussed.

\section{Estimated Variables}

The following variables, which relate to the characteristics of patient, lesion and implanted stents, were compared in the 3 groups: age (in years); ratio of males (male sex); hypertension; diabetes mellitus; hyperlipidemia; prior myocardial infarction; multiple vessel disease (multi-VD); left ventricular dysfunction (defined as having an ejection fraction $<40 \%$ ); complex lesion classified as type B2/C, in accordance with the ACC/AHA task classification (type B2/C); chronic total occlusion lesion; acute myocardial infarction; use of rotablator (rotablator); the availability of IVUS (IVUS-guide; as defined above); number of implanted stents (stent number); maximum balloon size used to expand the stent (stent diameter); total stented segment length (stent length); and balloon pressure used for the maximal size balloon (Maximum pressure).

\section{Statistic Analysis}

The variable values were expressed as the mean \pm standard deviation (SD). The aforementioned variables and the incidences of endpoints were statistically compared using unpaired t-test for continuous variables or chi-square test for categorical variables. All statistical analysis was verified as significant when the $\mathrm{p}$-value was $<0.05$. The statistical program SPSS for Windows version 11.5 (SPSS, Inc, Chicago, IL, USA) was used for carrying out the statistical analysis.

\section{Results}

Comparison of the Characteristic Variables of Patient, Lesion, and Implanted Stents Among the 3 Experimental Groups

Among the 13 variables for the characteristics of patient and lesion, the ratios of hypertension, hyperlipidemia, AMI, and use of rotablator in the SES-RCAos group were significantly different from those in the BMS-RCAos group $(\mathrm{p}<0.05$, respectively) (Table 1$)$. But the percentage of calcification in the SES-RCAos $(5.4 \%)$ was not significantly different from that of the BMS-RCAos $(19.4 \%)(\mathrm{p}=0.085)$ (Table 1).
The ratios of hypertension, hyperlipidemia, type B2/C, AMI and prior myocardial infarction in the SES-RCAos group were significantly different from those in the SESRCApro group ( $\mathrm{p}<0.05$, respectively) (Table 1$)$.

In the present study, the patient with chronic hemodialysis was not included. The ratios of IVUS-guide use were not significantly different among the 3 groups.

Regarding the characteristics of implanted stents, 4 variables were compared in the 3 groups. The number of stents used in the SES-RCApro was significantly less compared with the other 2 groups $(\mathrm{p}<0.05)$ (Table 1). Diameter of implanted stent was not significantly different among the 3 groups (Table 1$)$. The stent length $(26.1 \pm 13.6 \mathrm{~mm})$ and maximum pressure used in the BMS-RCAos group were significantly shorter and lower compared with the SESRCAos $(17.4 \pm 7.73 \mathrm{~mm})$ and SES-RCApro groups $(\mathrm{p}<0.05$, respectively) (Table 1 ).

\section{Comparison of the Parameters of QCA and MACE Among} the 3 Experimental Groups

All of the 4 pre-procedural parameters (ie, MLD, \%DS, $\mathrm{RD}$ and lesion length) in the SES-RCAos group were not significantly different from those in the BMS-RCAos and SES-RCApro groups (Table 2).

Regarding the parameters for post-procedural phase, all of the 4 post-procedural parameters (ie, MLD, \%DS, RD and acute gain) in the SES-RCAos group were not significantly different from those in the BMS-RCAos group (Table 2). However, MLD, RD and acute gain in the SESRCAos group were significantly different from those in the SES-RCApro group.

Regarding the parameters at chronic phase, the mean interval between the f-CAG in the SES-RCAos group (243 \pm 93 day) was significantly longer than that in the BMSRCAos group (194 \pm 71.2 day, $\mathrm{p}<0.05)$ (Table 2). Except for $\mathrm{RD}$, all of the parameters (ie, MLD, \%DS, late luminal loss, binary restenosis (18.9\%) and the ratio of focal type ISR $(71.4 \%)$ ) in the SES-RCAos group were significantly different from those in the BMS-RCAos group (eg, binary restenosis, 41.7\%; the ratio of focal type ISR, 6.7\%) $(\mathrm{p}<0.05, \mathrm{p}=0.017$, respectively $)$.

Binary restenosis $(4.84 \%)$ and late luminal loss in the SES-RCApro group were significantly smaller than those in the SES-RCAos group ( $\mathrm{p}<0.05$, respectively) (Table 2). However, the ratio of focal type ISR in the SES-RCApro group $(33.3 \%)$ was not significantly different from that in the SES-RCAos group ( $\mathrm{p}=0.69)$.

Regarding the variables for assessing clinical outcome, the ratio of TLR in the SES-RCAos group (13.5\%) was significantly decreased compared with that in the BMS-RCAos group (36.1\%; $\mathrm{p}<0.05)$, but was significantly increased compared with that in the SES-RCApro group (1.61\%; $\mathrm{p}<0.05)$ (Table 2). The number of cases of CABG for TLR was only 1 and 2 in the SES-RCAos and BMS groups, respectively. Incidences of death, myocardial infarction or definite stent thrombosis did not occur in any of the groups. Accordingly, the incident ratio of MACE in the SES-RCAos group (13.5\%) was significantly decreased compared with that in the BMS-RCAos group (36.1\%), but was increased compared with that in the SES-RCApro group (1.61\%) $(\mathrm{p}<0.05$, respectively).

\section{Discussion}

The present study was conducted to assess whether 
RCAos is consistently considered to be a limitation of PCI despite the availability of DES technology, as it has been reported that RCAos is the most powerful predictor for TLR of SES4 And, as reflected in the higher incidences of binary restenosis (3.9-fold increase) and TLR (8.39-fold increase) in the SES-RCAos group compared with the SESRCApro group (Table 2), RCAos was considered to be a limitation of SES because the benefits of SES1,2 (ie, the reduction of binary restenosis and TLR) were not exerted.

In the past, the clinical and angiographic outcomes after PCI to RCAos have been unacceptable after using various devices such as POBA, BMS,-11 and debulking with a DCA $^{12}$ or a rotablator ${ }^{13}$ However, as the BX Velocity stent possesses potent radial force to scaffold the vascular wall, the SES (Cypher ${ }^{\circledR}$ stent), in which sirolimus is eluted on the BX Velocity stent, was expected to ameliorate RCAos by combining the effect of the radial scaffolding force of the BX Velocity stent with sirolimus, which suppresses the growth of neointima. However, as indicated in the present study and as discussed below, RCAos is considered a limitation of PCI even with today's DES technology. The significant increase in binary restenosis (significantly larger late luminal loss) after SES implantation to RCAos compared with RCApro was the overall expression of the following causative factors for ISR. At first, RCAos was plentiful for the elastic fiber owing to the geometrical access form aorta. Therefore, not only early but also late elastic recoil occurred frequently, although larger acute gain was obtained after stent implantation with high pressure dilatation (Table 2), 26-28 In addition, it is reported that the tissues at the RCAos are frequently sclerotic due to the combination of calcification and fibrosis. Usually, this might implicate in-stent underexpansion ${ }^{20,21}$ and/or nonuniform expansion ${ }^{29}$ which are the major intravascular findings of ISR after SES implantation. Furthermore, stent fracture $^{30}$ induced by hinge motion and/or overexpansion after stent implantation to RCAos makes sirolimus eluted on the fractured stent less effective. Thus, for these reasons for restenosis, although SES exerted greater benefits than BMS to RCAos (eg, 55\% reduction of binary restenosis and $63 \%$ reduction of TLR) (Table 2), RCAos became the most powerful predictor of TLR of SES ${ }^{3,4}$ and, in turn, became a limitation of PCI. Therefore, an histological assessment revised from previous reports ${ }^{26,27}$ suggests that in order to ascertain the impact of sirolimus for RCAos, a detailed intravascular estimation, particularly at RCAos (limitation is discussed later), and mechanical effects, such as hinge motion and stent fracture, after stent implantation to RCAos (limitation is discussed later) must be identified to overcome the limitation of PCI at RCAos.

\section{Study Limitations}

Several limitations of the present study must be taken into account. First, the present study was a retrospective, non-randomized and single-center small study, so a further large-scale prospective study with more long-term observation, including the outcome of re-TLR, is needed to estimate the impact of RCAos. Second, a detailed intravascular assessment would further confirm the impact of the present study in estimating angiographic outcome. However, as described above in Methods (which describes the definition of IVUS-guide used in the present study), the differences in the intravascular assessments among the 3 groups could not be fully compared. Third, according to the present study, further revision (eg, combining SES implantation to RCAos with pulverizing calcification by rotablator to facilitate stent dilation) might be effective because the ratio of rotablator use in the SES-RCAos group was significantly decreased compared with that in the BMS-RCÁos group (Table 1). However, acute gain in the SES-RCAos group was the same as that in the BMS-RCAos group (Table 2). In addition, rotablator use before SES implantation for the treatment of heavily calcified coronary lesions did not exert the expected beneficial effects of reducing the TLR ratio compared with post-SES implantation without rotablator ${ }^{31}$ Furthermore, the ratios of calcification and rotablator use in the SES-RCAos group were not significantly different from those in the SES-RCApro group. Therefore, rotablator use for calcified RCAos before SES implantation on binary restenosis and TLR might not influence our interpretation of the present study's results. Finally, stent fracture ${ }^{30}$ one of the possible factors for ISR, as described above, could not be conclusively estimated by angiographic and intravascular assessments, as described in the second limitation.

\section{Conclusion}

In conclusion, although SES exerted greater benefit in reducing the incidences of binary restenosis and TLR compared with BMS to RCAos, RCAos is considered to be a limitation of SES, owing to its markedly increased incident ratios of binary restenosis and TLR compared with RCApro.

\section{References}

1. Morice MC, Serruys PW, Sousa JE, Fajadet J, Ban Hayashi E, Perin M, et al; RAVEL Study Group. Randomized Study with the SirolimusCoated Bx Velocity Balloon-Expandable Stent in the Treatment of Patients with de Novo Native Coronary Artery Lesions. A randomized comparison of a sirolimus-eluting stent with a standard stent for coronary revascularization. $N$ Engl J Med 2002; 346: 1773-1780.

2. Moses JW, Leon MB, Popma JJ, Fitzgerald PJ, Holmes DR, O'Shaughnessy C, et al; SIRIUS Investigators. Sirolimus-eluting stents versus standard stents in patients with stenosis in a native coronary artery. $N$ Engl J Med 2003; 349: 1315-1323.

3. Lemos PA, Hoye A, Goedhart D, Arampatzis CA, Saia F, van der Giessen WJ, et al. Clinical, angiographic, and procedural predictors of angiographic restenosis after sirolimus-eluting stent implantation in complex patients: An evaluation from the Rapamycin-Eluting Stent Evaluated At Rotterdam Cardiology Hospital (RESEARCH) study. Circulation 2004; 109: 1366-1370.

4. Mutoh M, Ishikawa T, Hasuda T, Okada H, Endo A, Miyanaga S, et al. Predictors of target lesion revascularization and documented stent thrombosis beyond 30 days after sirolimus-eluting stent implantation: Retrospective analysis in consecutive 1070 angiographic follow-up lesions. Circ J 2007; 71: 1328-1331.

5. Costa MA, Simon DI. Molecular basis of restenosis and drug-eluting stents. Circulation 2005; 111: 2257-2273 (Review).

6. Lemos PA, van Mieghem CA, Arampatzis CA, Hoye A, Ong AT, McFadden E, et al. Post-sirolimus-eluting stent restenosis treated with repeat percutaneous intervention: Late angiographic and clinical outcomes. Circulation 2004; 109: 2500-2502.

7. Topol EJ, Ellis SG, Fishman J, Leimgruber P, Myler RK, Stertzer $\mathrm{SH}$, et al. Multicenter study of percutaneous transluminal angioplasty for right coronary artery ostial stenosis. J Am Coll Cardiol 1987; 9: 1214-1218.

8. Zampieri P, Colombo A, Almagor Y, Maiello L, Finci L. Results of coronary stenting of ostial lesions. Am J Cardiol 1994; 73: 901-903.

9. Tsunoda T, Nakamura M, Wada M, Ito N, Kitagawa Y, Shiba M, et al. Chronic stent recoil plays an important role in restenosis of the right coronary ostium. Coron Artery Dis 2004; 15: 39-44.

10. Mavromatis K, Ghazzal Z, Veledar E, Diamandopoulos L, Weintraub WS, Douglas JS, et al. Comparison of outcomes of percutaneous coronary intervention of ostial versus nonostial narrowing of the major epicardial coronary arteries. Am J Cardiol 2004; 94: 583-587.

11. Jain SP, Liu MW, Dean LS, Babu R, Goods CM, Yadav JS, et al. Comparison of balloon angioplasty versus debulking devices versus 
stenting in right coronary ostial lesions. Am J Cardiol 1997; 79: $1334-1338$.

12. Popma JJ, Dick RJ, Haudenschild CC, Topol EJ, Ellis SG. Atherectomy of right coronary ostial stenoses: Initial and long-term results, technical features and histologic findings. Am J Cardiol 1991; 67: $431-433$.

13. Motwani JG, Raymond RE, Franco I, Ellis SG, Whitlow PL. Effectiveness of rotational atherectomy of right coronary artery ostial stenosis. Am J Cardiol 2000; 85: 563-567.

14. Iakovou I, Ge L, Michev I, Sangiorgi GM, Montorfano M, Airoldi F, et al. Clinical and angiographic outcome after sirolimus-eluting stent implantation in aorto-ostial lesions. J Am Coll Cardiol 2004; 44: 967-971.

15. Park DW, Hong MK, Suh IW, Hwang ES, Lee SW, Jeong YH, et al. Results and predictors of angiographic restenosis and long-term adverse cardiac events after drug-eluting stent implantation for aortoostial coronary artery disease. Am J Cardiol 2007; 99: 760-765.

16. Ishikawa T, Mutoh M, Fuda Y, Sakamoto H, Okada H, Satoh T, et al. Documented subacute stent thrombosis within 30 days after primary stenting with sirolimus-eluting stent $\left(\right.$ Cypher $\left.^{\circledR}\right)$ in acute myocardial infarction: A Japanese single-center retrospective non-randomized study. Circ J 2006; 70: 1091-1092.

17. Sakamoto H, Ishikawa T, Mutoh M, Okada H, Tsurusaki T, Ohta M, et al. Effectiveness of a sirolimus-eluting stent $\left(\right.$ Cypher $\left.^{\circledR}\right)$ for diffuse in-stent restenosis inside a bare metal stent. Int Heart J 2006; 47: $651-661$.

18. United States Food and Drug Administration (FDA). Clinical Overview for Panel Packet; DES thrombosis panel 1-32, Dec 7-8, 2006.

19. Cheneau E, Satler LF, Escolar E, Suddath WO, Kent KM, Weissman $\mathrm{NJ}$, et al. Underexpansion of sirolimus-eluting stents: Incidence and relationship to delivery pressure. Catheter Cardiovasc Interv 2005; 65: $222-226$.

20. Fujii K, Carlier SG, Mintz GS, Yang YM, Moussa I, Weisz G, et al. Stent underexpansion and residual reference segment stenosis are related to stent thrombosis after sirolimus-eluting stent implantation: An intravascular ultrasound study. J Am Coll Cardiol 2005; 45: 995-998.

21. Eisenstein EL, Anstrom KJ, Kong DF, Shaw LK, Tuttle RH, Mark
DB, et al. Clopidogrel use and long-term clinical outcomes after drug-eluting stent implantation. JAMA 2007; 297: 159-168.

22. Kimura T, Nosaka H, Yokoi H, Iwabuchi M, Nobuyoshi M. Serial angiographic follow-up after Palmaz-Schatz stent implantation: Comparison with conventional balloon angioplasty. J Am Coll Cardiol 1993; 21: $1557-1563$.

23. Fajadet J, Morice MC, Bode C, Barragan P, Serruys PW, Wijns W, et al. Maintenance of long-term clinical benefit with sirolimus-eluting coronary stents: Three-year results of the RAVEL trial. Circulation 2005; 111: 1040-1044.

24. Mauri L, Orav EJ, Candia SC, Cutlip DE, Kuntz RE. Robustness of late lumen loss in discriminating drug-eluting stents across variable observational and randomized trials. Circulation 2005; 112: $2833-$ 2839.

25. Mehran R, Dangas G, Abizaid AS, Mintz GS, Lansky AJ, Satler LF, et al. Angiographic patterns of in-stent restenosis: Classification and implications for long-term outcome. Circulation 1999; 100: $1872-$ 1878.

26. Stewart JT, Ward DE, Davies MJ, Pepper JR. Isolated coronary ostial stenosis: Observations on the pathology. Eur Heart J 1987; 8: 917-920.

27. Rissanen V. Occurrence of coronary ostial stenosis in a necropsy series of myocardial infarction, sudden death, and violent death. $\mathrm{Br}$ Heart J 1975; 37: 182-191.

28. Applegate RJ, Draughn T, Yarbrough WD, Little WC. Restenosis of a sirolimus drug-eluting stent: Aorto-ostial involvement of the proximal right coronary artery. Catheter Cardiovasc Interv 2006; 67: $391-$ 395.

29. Takebayashi H, Mintz GS, Carlier SG, Kobayashi Y, Fujii K, Yasuda T, et al. Non-uniform strut distribution correlates with more neointimal hyperplasia after sirolimus-eluting stent implantation. Circulation 2004; 110: 3430-3434.

30. Sianos G, Hofma S, Ligthart JM, Saia F, Hoye A, Lemos PA, et al. Stent fracture and restenosis in the drug-eluting stent era. Catheter Cardiovasc Interv 2004; 61: 111-116.

31. Clavijo LC, Steinberg DH, Torguson R, Kuchulakanti PK, Chu WW, Fournadjiev J, et al. Sirolimus-eluting stents and calcified coronary lesions: Clinical outcomes of patients treated with and without rotational atherectomy. Catheter Cardiovasc Interv 2006; 68: 873-878. 